\title{
ABSTRACTS OF COMMUNICATIONS Proceedings of the Thirty-first Meeting of the Agricultural Research Modellers' Group
}

\author{
EDITED BY \\ J. FRANCE AND L. A. CROMPTON \\ The University of Reading, Department of Agriculture, Earley Gate, Reading RG6 6AT, UK
}

This group, which is concerned with the applications of mathematics to agricultural science, was formed in 1970 and has since met at approximately yearly intervals in London for one-day meetings. The thirty-first meeting of the group, chaired by Professor M. Gill of NR International, Chatham, was held in the Kohn Centre at the Royal Society, 6 Carlton House Terrace, London on Friday, 16 April 1999 when the following papers were read.

Linking GIS and dynamic SOM models: estimating the regional carbon sequestration potential of agricultural management options. P. D. FALLOON ${ }^{1}, \mathrm{P}$. SMITH $^{1}$, J. S. ZABÓ ${ }^{2}$, L. PASZTOR ${ }^{2}$, J. U. SMITH $^{1}$, K. COLEMAN ${ }^{1}$ AND S. MARSHALL ${ }^{3}$. ${ }^{1}$ Soil Science Department, IACR-Rothamsted, Harpenden, Herts AL5 $2 J Q, U K,{ }^{2}$ GIS Laboratory, RISSAC, Herman Otto Utca 15, Budapest 1022, Hungary, ${ }^{3}$ School of Biology, University of Nottingham, Sutton Bonington Campus, Loughborough, LE12 5RD, UK

Soil organic matter (SOM) represents a major pool of carbon within the biosphere, estimated at approximately $1400 \mathrm{Pg}$ globally, roughly twice that present in atmospheric $\mathrm{CO}_{2}$. The soil can act as both a source and a sink for carbon and nutrients. Changes in agricultural land-use and climate can lead to changes in the amount of carbon held in soils, in this way affecting the fluxes of $\mathrm{CO}_{2}$ to and from the atmosphere. Some agricultural management practices will lead to a net sequestration of carbon in the soil. Regional estimates of the carbon sequestration potential of these practices are crucial if policy makers are to plan future land-uses to reduce national $\mathrm{CO}_{2}$ emissions.

In Europe, carbon sequestration potential has previously been estimated using data from the Global Change and Terrestrial Ecosystems SOM Network (SOMNET; Smith et al. 1996). Linear relationships between management practices and yearly changes in soil organic carbon were developed and used to estimate changes in the total carbon stock of European soils (e.g. Smith et al. 1998). To refine these semi-quantitative estimates, the local soil type, meteorological conditions and land-use must also be taken into account. We have previously used the Rothamsted Carbon Model (RothC; Coleman \& Jenkinson 1996) linked to Geographical Information Systems (GIS) to estimate the potential effects of afforestation on soil carbon stocks in Central Hungary (Falloon et al. 1998). Further developments have involved using both RothC and the CENTURY model (Parton et al. 1987). The GIS-linked system integrates land use, soil and weather data with knowledge of land-use history, local agricultural practices and best estimates of the current stock of soil organic carbon. We use an area of Central Hungary to compare (i) model estimates of current carbon stocks using RothC and CENTURY and (ii) results of carbon sequestration potential estimated with this system to a regression-based approach, for a simple afforestation scenario. RothC and CENTURY parameters were set using data from SOMNET. With a total carbon stock for the area of $0.93 \mathrm{Tg}$ carbon (to $20 \mathrm{~cm}$ ) and a scenario of afforestation of all arable land, carbon sequestration over 100 years predicted by CENTURY, RothC, and the regression (Smith et al. 1998) was $0 \cdot 15,0 \cdot 31$ and $1 \cdot 02 \mathrm{Tg}$ carbon (to $20 \mathrm{~cm}$ ) respectively.

Coleman, K. \& Jenkinson, D. S. (1996). RothC-26.3 - A model for the turnover of carbon in soil. In Evaluation of Soil Organic Matter Models Using Existing, Long-Term Datasets (Eds D. S. Powlson, P. Smith \& J. U. Smith), NATO ASI Series I 38, 237-246. Heidelberg: SpringerVerlag.

Falloon, P. D., Smith, P., Smith, J. U., Szabo, J., Coleman, K. \& Marshall, S. (1998). Regional estimates of carbon sequestration potential: linking the Rothamsted Carbon 
Turnover model to GIS databases. Biology and Fertility of Soils 27, 236-241.

Parton, W. J., Schimel, D. S., Cole, C. V. \& Ojima, D. (1987). Analysis of factors controlling soil organic levels of grasslands in the Great Plains. Soil Science Society of America Journal 58, 530-536.

Smith, P., Powlson, D. S., Smith, J. U. \& Glendining, M. J. (1996). The GCTE SOMNET. A global network and database of soil organic matter models and long-term datasets. Soil Use and Management 12, 104.

Smith, P., Powlson, D. S., Glendining, M. J. \& Smith, J. U. (1998). Preliminary estimates of the potential for carbon mitigation in European soils through no-till farming. Global Change Biology 4, 679-685.

Modelling photosynthetic acclimation to $\mathrm{CO}_{2}$, light, nitrogen and temperature. J. H. M. THORNLEY. The University of Reading, Department of Agriculture, Reading RG6 6AT, UK; Institute of Terrestrial Ecology, Edinburgh EH26 OQB, UK; 6 Makins Road, Henley-on-Thames, Oxon RG9 1PP, $U K$

When modelling plant ecosystems, simple but realistic submodels of important processes such as photosynthesis are required. A suitable model of $\mathrm{C}_{3}$ leaf photosynthetic acclimation is described, developing an earlier model (Thornley 1998a). This extends the empirical use of a non-rectangular hyperbola (NRH) for photosynthesis. The model allows the high-light asymptote of the NRH $\left(P_{\text {max }}\right)$ to respond dynamically to $\mathrm{CO}_{2}$, light, nitrogen $(\mathrm{N})$ and temperature. It is assumed that photosynthetic $\mathrm{N}$ is synthesized from foliage substrate $\mathrm{N}$ by a light-driven reaction. Photosynthetic $\mathrm{N}$ can be degraded back to substrate $\mathrm{N}$. $P_{\max }$ is proportional to photosynthetic $\mathrm{N}$ content. This causes the leaf light response equation to acclimate continuously to the current environment. This acclimatory response is important when predicting the effects of seasonal and short-term changes in environment, as well as longer-term climate changes. The model, with its one extra compartment, has successfully been incorporated into two plant ecosystem models: the Hurley Pasture Model (HPM) (Thornley 1998b), and the Edinburgh Forest Model (Thornley \& Cannell 1996)*. Using the HPM, predictions of photosynthetic acclimation to step changes in $\mathrm{CO}_{2}$, light, $\mathrm{N}$ deposition, and temperature are presented. The model predicts a variable down/up regulation of photosynthesis in response to increased $\mathrm{CO}_{2}$, which depends on conditions, particularly of $\mathrm{N}$ nutrition. The approach may be of value to plant ecosystem modellers, because of the need for transparent accurate submodels.

* ACSL programs PASTURE.CSL and FOREST.CSL are obtainable from the author or by ftp from budbase.nbu.ac.uk/pub/tree/Pasture and budbase.nbu. ac.uk/pub/tree/Forest.
Thornley, J. H. M. \& CAnnell, M. G. R. (1996). Temperate forest responses to carbon dioxide temperature and nitrogen, a model analysis. Plant Cell and Environment 19, $1331-1348$

Thornley, J. H. M. (1998a). Dynamic model of leaf photosynthesis with acclimation to light and nitrogen. Annals of Botany 81, 421-430.

ThORnLey, J. H. M. (1998b). Grassland Dynamics: An Ecoystem Simulation Model. xii, 241. Wallingford: CAB International.

WINSORG: a new process-based model for predicting dry matter production of sorghum grown in southern Europe. M. J. MARTIN ${ }^{1}$, S. W. HUMPHRIES ${ }^{2}$ AND S. P. LONG ${ }^{3}$. ${ }^{1}$ Department of Biological Sciences, University of Essex, Wivenhoe Park, Colchester, Essex CO4 3SQ, UK, ${ }^{2}$ Brookhaven National Laboratory, Upton, New York, 11973, USA, ${ }^{3}$ University of Illinois, Departments of Crop Sciences and Plant Biology, 190 Edward R. Madigan Laboratory, 1201 West Gregory Drive, Urbana, IL61801, USA

Overproduction of arable crops and formal commitments to decrease carbon emissions have promoted the search for potential energy crops within the European Union (EU). Sorghum, which is well suited to growth in the dry, relatively nutrient-poor soils of southern Europe, is one crop being actively considered. With a relatively short timeframe for implementation, extensive trials over several years are not an option. Therefore, limited trials are in place and are used to test mechanistic models of crop production that will allow prediction of yields over a wider area and with year-to-year variation in weather. Development and testing of a model, WINSORG, is described here. The aim was to create a user-friendly model that predicts the growth of sorghum in southern Europe, by combining the canopy carbon dioxide, water and energy exchange model within WIMOVAC (Humphries \& Long 1995) with the phenomenological partitioning of the crop growth model CERESSorghum, adapted for European sorghum by INRA (Medeiros 1997).

To facilitate access to agronomists within the same EU project, the model with its assumptions, equations, parameters and output are fully accessible through a Windows ${ }^{\text {(im }}$ environment. WINSORG includes algorithms that describe low temperature stress, high temperature enhancement and water stress effects on above ground dry matter production of sorghum. The model was parameterized using INRA data on sorghum grown in southern Europe during the early 1990s (Medeiros 1997).

When tested against independent data using abiotic model inputs of latitude, mean daily air temperature, sowing date, watering regime and soil characteristics of the site, the model closely simulated the trends in dry matter production of sorghum grown at seven locations around southern Europe in 1997. 
This research was funded by the European Community: Contract FAIR CT96-1913 - Environmental Studies on Sweet and Fibre Sorghum, Sustainable Crops for Biomass and Energy.

Humphries, S. W. \& Long, S. P. (1995). wimovaC: a software package for modelling the dynamics of plant leaf and canopy photosynthesis. CABIOS (Computer Applications in BioSciences) 11, 361-371.

MedeIros, S. L. P. (1997). Amelioration et optimisation du module contrainte hydrique dans le modele CERESSorghum. PhD thesis, Institut National Agronomique Paris-Grignon-INAPG.

A modified growth rate equation for the crop nitrogen simulation model N-ABLE. J. YANG ${ }^{1}$, G. A. WADSWORTH $^{1}$, D. L. ROWELL ${ }^{1}$ AND I. G. BURNS ${ }^{2} .{ }^{1}$ The University of Reading, Department of Soil Science, Whiteknights, PO Box 233, Reading RG6 6DW, UK, ${ }^{2}$ Department of Soil and Environment Sciences, Horticulture Research International, Wellesbourne, Warwick CV35 9EF, UK

The crop nitrogen simulation model, N-ABLE, uses an equation that predicts dry weights which follow a $\mathrm{J}$-shaped growth curve by a differential equation (Greenwood et al. 1996):

$$
\frac{\mathrm{d} W}{\mathrm{~d} T}=G_{\mathrm{f}} G_{\mathrm{s}} \frac{K_{2} W}{\left(K_{1}+W\right)} \quad\left(T_{\mathrm{p}} \leqslant T \leqslant T_{\mathrm{h}}\right)
$$

where $W$ is dry weight $\left(\mathrm{t} \mathrm{ha}^{-1}\right)$ at time $T$ (day since 1 st January). $K_{1}$ is a growth constant set to $1 \mathrm{t} /$ ha for all crops (Greenwood \& Draycott 1989) and $K_{2}$ is a crop dependent coefficient indicating ample mineral nitrogen $(\mathrm{N})\left(\right.$ e.g. $\left.G_{\mathrm{f}}=1\right) . G_{\mathrm{f}}$ is a correction coefficient to allow for sub-optimal $\% \mathrm{~N}$ in the crop (e.g. $G_{\mathrm{f}}=$ $\min \left(P_{\mathrm{n}} / P_{\text {crtn }}, 1 \cdot 0\right)$, where $P_{\mathrm{n}}$ is the actual $\% \mathrm{~N}$ in $W$ and $P_{\text {crtn }}$ is critical \% N in $\left.W\right) ; G_{\mathrm{s}}$ is a soil temperature dependent coefficient (e.g. $G_{\mathrm{s}}=G_{\mathrm{s}}(t)$ ) (Greenwood et al. 1996). $K_{2}$ is calculated from the integral of Equation 1:

$$
K_{2}\left[K_{1}\left(\ln W_{\mathrm{m}}-\ln W_{\mathrm{p}}\right)+\left(W_{\mathrm{m}}-W_{\mathrm{p}}\right)\right] /\left(T_{\mathrm{h}}-T_{\mathrm{p}}\right)
$$

where $W_{\mathrm{m}}$ is the potential maximum dry weight at harvest $\left(T_{\mathrm{h}}\right)$ and $W_{\mathrm{p}}$ is dry weight at planting $\left(T_{\mathrm{p}}\right)$.

However, the curve for lettuce from a field trial fitted an S-shaped curve for the whole growth period (Yang et al. 1999). As a result, the growth model (Equation 1) only described the exponential part of the growth curve accurately. For longer periods of growth, an asymmetrical S-shaped growth equation was developed:

$$
\begin{gathered}
\frac{\mathrm{d} W}{\mathrm{~d} T}=G_{\mathrm{f}} G_{\mathrm{s}} \frac{K_{2} W}{\left(K_{1}+W\right)} \quad\left(T_{\mathrm{p}} \leqslant T \leqslant T_{\mathrm{k}}\right) \\
\frac{\mathrm{d} W}{\mathrm{~d} T}=G_{\mathrm{f}} G_{\mathrm{s}} G_{\mathrm{k}} \frac{K_{2} W}{\left(K_{1}+W\right)} \quad\left(T_{\mathrm{k}} \leqslant T \leqslant T_{\mathrm{h}}\right) \\
G_{\mathrm{k}}=\left(\frac{W_{\mathrm{k}}}{\mathrm{W}}\right)^{n}
\end{gathered}
$$

where $G_{\mathrm{k}}(\leqslant 1)$ is a coefficient which allows for a decrease in the growth rate due to physiological or other reasons in the later part of the growth period. $G_{\mathrm{k}}=1$ when $T=T_{\mathrm{k}}, G_{\mathrm{k}}<1$ when $T>\mathrm{T}_{\mathrm{k}}$ and the value of $G_{\mathrm{k}}$ becomes smaller with time $T$. $W_{\mathrm{k}}$ is plant dry weight at day $T_{\mathrm{k}}\left(T_{\mathrm{p}}<T_{\mathrm{k}} \leqslant T_{\mathrm{h}}\right), n$ is a curvature coefficient, $K_{2}$ is calculated from the integral of Equation 2:

$$
K_{2}=\left[K_{1}\left(\ln W_{\mathrm{k}}-\ln W_{\mathrm{p}}\right)+\left(W_{\mathrm{k}}-W_{\mathrm{p}}\right)\right] /\left(T_{\mathrm{k}}-T_{\mathrm{p}}\right)
$$

When $T<\mathrm{T}_{\mathrm{k}}$, Equation 2 works, and the model can simulate a J-shaped growth curve for the first period of the growth. When $T>T_{\mathrm{k}}$, Equation 3 works and daily growth rate of dry weight $(\mathrm{d} W / \mathrm{d} T)$ slows down gradually by the modification of $G_{\mathrm{k}}$ because $G_{\mathrm{k}}<1$ and the growth curve has an S-shape for the whole period of the growth. $G_{\mathrm{k}}$ works interactively with $G_{\mathrm{s}}$ : when soil temperature is lower, growth rate $\mathrm{d} W / \mathrm{d} T$ slows down quickly due to $G_{\mathrm{s}}$, and $G_{\mathrm{k}}$ has a reduced effect, e.g. $\left(W_{\mathrm{k}} / \mathrm{W}_{\mathrm{i}-1}\right) \approx\left(W_{\mathrm{k}} / \mathrm{W}_{\mathrm{i}}\right),(i=$ days $)$. If soil temperature does not change, growth rate $\mathrm{d} W / \mathrm{d} T$ slows gradually due to $G_{\mathrm{k}}$ because $W_{\mathrm{i}-1}<W_{\mathrm{i}}$.

The modified growth equation was well calibrated using linear relationships $W_{\mathrm{k}}=\alpha W_{\mathrm{m}}$ and $T_{\mathrm{k}}=$ $T_{\mathrm{p}}+\beta\left(T_{\mathrm{h}}-T_{\mathrm{p}}\right)$, where $W_{\mathrm{m}}, T_{\mathrm{p}}$ and $T_{\mathrm{h}}$ are known input parameters. It was found that $\alpha=0 \cdot 7, \beta=0.6$ and $n$ $=2$ gave the best fit for lettuce data, and a lack of fit test (Whitmore 1991) shows that the residual errors were not significantly different from experimental errors (Yang et al. 1999). Further evaluations were made using Norwegian field data (Riely \& Guttormsen 1993), and $\alpha=0.6, \beta=0.6$ and $n=0.5$ were found to give the best fit to most of the data for winter cabbage in both sandy and loamy soils in 1990 and 1994.

This work was founded by an ORS award and we are grateful to H. Riely and G. Guttormsen for providing field data for model evaluation.

Greenwood, D. J. \& Draycott, A. (1989). Experimental validation of an N-response model for widely different crops. Fertiliser Research 18, 153-174.

Greenwood, D. J., Rahn, C. R., Draycott, A., Vaidyanathan, L. V. \& Paterson, C. (1996). Modelling and measurement of the effects of fertiliser- $\mathrm{N}$ and crop residue incorporation on N-dynamics in vegetable cropping. Soil Use and Management 12, 13-24.

Riely, H. \& GutToRmsen, G. (1993). N requirements for cabbage crops grown on contrasting soils. I: Field trials. Norwegian Journal of Agricultural Science 7, 275-291.

Whitmore, A. P. (1991). A method for assessing the goodness of computer simulation of soil processes. Journal of Soil Science 42, 289-299.

Yang, J., Wadsworth, G. A., Rowell, D. L. \& Burns, I. G. (1999). Evaluating a crop nitrogen simulation model, N-ABLE, using a field experiment with lettuce. Nutrient Cycling in Agroecosystems (in press). 
A model of peat growth in a raised bog: outputs and analysis. A. J. GILMER ${ }^{1}$, S. M. WARD ${ }^{1}$, A. BRERETON $^{1}$, N. M. HOLDEN ${ }^{1}$ AND E. P. FARRELL ${ }^{2} .{ }^{1}$ University College Dublin, Earlsfort Terrace, Dublin 2, Ireland, ${ }^{2}$ Department of Environmental Resource Management, University College Dublin, Belfield, Dublin 4, Ireland

Two process zones have been distinguished in raised peat formations: an upper aerobic layer called the acrotelm and a deeper anaerobic layer called the catotelm (Ingram 1978). Clymo (1984) has advanced a model approach defining the dynamics of the accumulation and decomposition processes with respect to these zones, where all organic matter is ultimately treated as labile. The model approach adopted here differs from that position in that the peat profile is built from the addition of parcels comprising both a labile and a non-labile component. Parcel bulk density is used to determine the depth at which the acrotelm/catotelm boundary arises. The approach uses parameters and variables drawn mainly from published sources in Fennoscandia, Britain and Ireland. The model identifies three process zones, namely (i) the acrotelm or aerobic zone of decomposition, (ii) the upper catotelm where anaerobic decomposition of the labile fraction is relatively greater than the lower catotelm, and (iii) the lower catotelm where decomposition is minimal due to the ever reducing fractions of labile material present. The model generates profiles of peat depth and mass with time and profiles of the change in the bulk density with depth. Sensitivity analysis was performed on the model. Model output for depth and mass was most sensitive to primary productivity. This parameter was modified to establish a better fit with reported field data for an undisturbed Irish raised bog. Data ranges used to determine the profiles demonstrate some slowing in growth as it approaches what may be regarded as a steady state. Further growth then approximates a linear relationship with time. The existence of a non-labile component ensures this growth pattern. Thus, when the peat profile matures to this point, further growth approaches a constant, which is directly proportional to the non-labile fraction added in primary productivity.

Clymo, R. S. (1984). The limits of peat bog growth. Philosophical Transactions Royal Society London B303, 605-654.

Ingram, H. A. P. (1978). Soil layers in mires: function and terminology. Journal of Soil Science 29, 224-227.
What is the critical timescale of a cow's feeding behaviour? D. J. ALLCROFT ${ }^{1}$, C. A. GLASBEY ${ }^{1}$, I. KYRIAZAKIS ${ }^{2}$ AND B. J. TOLKAMP ${ }^{2}$. 1 Biomathematics and Statistics Scotland, The King's Buildings, Edinburgh EH9 3JZ, UK, ${ }^{2}$ Animal Biology Division, Scottish Agricultural College, The King's Buildings, Edinburgh EH9 3JG, UK

If we look at a cow's food intake over time, we see that on a short timescale, e.g. hourly, the intake is very variable. However, if we consider whole months, intake is very consistent from one month to the next. The question we are interested in is: can we pick out a timescale over which a cow regulates her food intake? Does the variability of her intake simply decrease as we lengthen the timescale, or can we find some particular length of time that has both some special statistical property and relevant biological meaning?

The data used were from an experiment recording the feeding behaviour of 8 cows with continuous access to a silage/concentrate feed in computerized feeders over a 30 day period. For each cow, let $x$ denote a time series, with $x_{t}$ the proportion of time spent eating during minute $t$ (note that rate of eating is fairly constant and so intake is roughly proportional to time spent eating). We can then look at the autocorrelation properties of this series, or alternatively consider the variance of all sums over $n$ minutes, $V_{\mathrm{n}}$, for $n=1,2,3, \ldots$

$$
V_{\mathrm{n}}=\operatorname{Var}\left(\sum_{t=1}^{n} x_{\mathrm{t}}\right)=n \sigma^{2}+2 \sigma^{2} \sum_{l=1}^{n-1}(n-\ell) \rho_{\ell}
$$

where $\sigma^{2}=\operatorname{Var}\left(x_{\mathrm{t}}\right)$ and $\rho_{l}$ is the autocorrelation of $x$ at lag $\ell$. Consideration of $V_{\mathrm{n}}$ for $n=1,2,3, \ldots$ is equivalent to looking at the set of autocorrelations $\rho_{\ell}$ for $\ell=1,2,3, \ldots$, but it is informative to look at both representations, as each will highlight different features of the data.

If $x$ were a series of independent random variables, all the correlation coefficients $\rho_{\ell}$ would be zero. In this case $V_{\mathrm{n}}$ would be proportional to $n$ and hence $V_{\mathrm{n}} / n$ would remain constant for any $n$. We are clearly not dealing with this case, as we have strong positive correlation at small lags. The data clearly displayed a diurnal effect (more strongly for some cows than others), so this was allowed for; the resulting picture was remarkably similar across all eight cows. $V_{n} / n$ increased up to a sharp peak at a time of around one hour and then decreased up to a time of one day, after which, on average, it remained fairly constant. This would indicate that for up to one hour, the change in $V_{\mathrm{n}} / n$ is being dominated by the short-lag positive correlations; after one hour, negative correlation is taking over, indicating some feedback, e.g. if the cow was eating at a particular time then she is unlikely to still be eating an hour later. The graph levelling out after one day points to there being no more feedback on timescales longer than one day. 
To investigate further the peak around one hour, an artificial series was created in which the cow alternates between eating for $a$ minutes and not eating for $b$ minutes. $V_{\mathrm{n}} / n$ for this series is a piecewise analytic function, the position of the maximum of which depends on the relative sizes of $a$ and $b$. Putting in typical values of 40 minutes feeding followed by an interval of 3.5 hours, the peak occurs at around one hour. This is obviously only a crude approximation of the real situation, but it is reassuring that we have a peak at a similar position as that observed from the data for each of the eight cows.

Therefore, we must conjecture that we have a critical timescale of a single day as use of this technique has produced no evidence of feedback over longer times than this. However, it is quite possible that another variable or technique might be able to detect food intake regulation over the longer term.

SOAEFD and BBSRC are thanked for funding this research.

\section{Modelling microbiological processes to explain ni- trous oxide production in drained peat soils. C. A. LANGEVELD AND P. A. LEFFELAAR. Laboratory of Theoretical Production Ecology, Wageningen University, P.O. Box 430, 6700 AK Wageningen, The Netherlands}

Pastures on drained peat soils are an important source of nitrous oxide $\left(\mathrm{N}_{2} \mathrm{O}\right)$, a greenhouse gas that is also involved in the depletion of the ozone layer. In the Netherlands, the contribution of peat soils to total $\mathrm{N}_{2} \mathrm{O}$ emissions is estimated at $12 \%$ (Langeveld et al. 1997).

Incubation experiments and modelling were performed to study the microbiological processes affecting the net production of $\mathrm{N}_{2} \mathrm{O}$ in drained peat. Soil samples were incubated in air-tight covered Petri dishes and $\mathrm{O}_{2}, \mathrm{CO}_{2}, \mathrm{~N}_{2} \mathrm{O}, \mathrm{N}_{2}, \mathrm{NO}_{3}^{-}, \mathrm{NO}_{2}^{-}, \mathrm{NH}_{4}{ }^{+}$and water soluble carbon were monitored. Methane was also monitored, but was never detected. Intermediate and end products were not removed. The relation between the results from this study on closed systems and $\mathrm{N}_{2} \mathrm{O}$ emissions in open systems needs to be established later.

The simulation model was adapted from earlier work (Leffelaar \& Wessel 1988). Monod functions from the literature were used to describe the kinetics of microbial processes. The functions do not describe end product inhibition. In addition to denitrification, aerobic respiration and mineralization of the dead bacterial biomass, the revised model includes mineralization of the soil organic matter and nitrification. These changes were to accomodate the different conditions described in our experiments (e.g. soil type, initial aerobic conditions of some treatments).

In the model, $\mathrm{N}_{2} \mathrm{O}$ production and utilization occurs during heterotrophic denitrification $\left(\mathrm{NO}_{3}{ }^{-} \rightarrow\right.$ $\mathrm{NO}_{2}{ }^{-} \rightarrow \mathrm{NO} \rightarrow \mathrm{N}_{2} \mathrm{O} \rightarrow \mathrm{N}_{2}$ ). Nitrous oxide produced during nitrification was not included, since information on the mechanism and the quantitative significance of this pathway is equivocal.

Agreement between the simulated and observed time courses for nitrogenous compounds, including $\mathrm{N}_{2} \mathrm{O}$, was satisfactory (visual inspection). However, the model underestimated the time course of $\mathrm{CO}_{2}$ under anaerobic conditions, which can be partly explained by the reduction of electron acceptors other than oxidized nitrogen compounds. These alternative electron acceptors might be organic compounds (Lovley et al. 1996) and their reduction could take place at highly reduced sites (sites with a low redox potential, e.g. the centres of soil aggregates, Smith \& Arah 1992), simultaneously with denitrification at less reduced sites.

Langeveld, C. A., Segers, R., Dirks, B. O. M., van den Pol-van Dasselaar, A., Velthof, G. L. \& Hensen, A. (1997). Emissions of $\mathrm{CO}_{2}, \mathrm{CH}_{4}$ and $\mathrm{N}_{2} \mathrm{O}$ from pasture on drained peat soils in the Netherlands. European Journal of Agronomy 7, 35-42.

LefFelaAR, P. A. \& Wessel, W. (1988). Denitrification in a homogeneous, closed system: experiment and simulation. Soil Science 146, 335-349.

Lovley, D. R., Coates, J. D., Blunt-Harris, E. L., Philips, E. J. P. \& Woodward, J. C. (1996). Humic substances as electron acceptors for microbial respiration. Nature 382, 445-448.

Smith, K. A. \& Arah, J. R. M. (1992). Measurement and modelling of nitrous oxide emissions from soils. Ecological Bulletins 42, 116-123.

A kinetic model for infinite urea recycling. G. ZUUR ${ }^{1}$ AND G. E. LOBLEY ${ }^{2} .{ }^{1}$ Biomathematics and Statistics Scotland, Rowett Research Institute, Greenburn Road, Bucksburn, Aberdeen AB21 9SB, $U K,{ }^{2}$ Rowett Research Institute, Greenburn Road, Bucksburn, Aberdeen AB21 9SB, UK

Not all urea produced by the liver $(P)$ is excreted in urine $(U)$. Part of the synthesized urea enters the gut $(G)$ and is hydrolysed to ammonia. This ammonia can undergo three fates, namely, microbial protein synthesis $(S)$, return to the ornithine cycle $\left(P_{\mathrm{r}}\right)$ and loss in faeces $(F)$. Partition between these fates can be determined through tracer kinetics based on doublelabelled $\left[{ }^{15} \mathrm{~N}^{15} \mathrm{~N}\right]$ urea infused into the body urea pool. $\left[{ }^{15} \mathrm{~N}\right]$ ammonia produced in the gut may be reabsorbed and recombine with unlabelled nitrogen to form single-labelled $\left[{ }^{14} \mathrm{~N}^{15} \mathrm{~N}\right]$ urea which is returned to the body urea pool. Monitoring the appearances of singleand double-labelled urea in blood or urine provides information on $P_{\mathrm{r}}$. The urea-N used for anabolic fates is calculated as $S=G-P_{\mathrm{r}}-F$.

Single entry models are based on the assumption that urea returned to the body urea pool via the ornithine cycle cannot re-enter the gut (Jackson et al. 
1984, 1993). This is an unrealistic scenario. Therefore, a model was developed which allows for multiple entry and return from the gut (Sarraseca et al. 1998). The probability that urea-N undergoes a series of conversions between ammonia and urea is modelled as a function of the proportion $1-u$ of urea production that enters the gut and the fraction $r$ recycled to the ornithine cycle.

However, loss of urea-N in faeces is not included in these models, resulting in overestimation of $S$. Furthermore, the model by Sarraseca et al. (1998) is applicable to continuous infusion experiments only. The following multiple entry model addresses these shortfalls by modelling faecal loss as a proportion $f$ of gut entry, and is generalized to include single shot experiments:

$$
\begin{aligned}
P & =U+G \\
G & =S+F+P_{\mathrm{r}} \\
G & =(1-u) P \\
P_{\mathrm{r}} & =\mathrm{rG} \\
F & =f G .
\end{aligned}
$$

This model was applied to data from a tracer kinetic experiment with five sheep fed on a maintenance diet of hay pellets. Values for $P, U$ and $G$ were $10 \cdot 395$, 2.393 and $8.302 \mathrm{~g}$ urea-N/d, respectively. Estimates for the fates of urea- $\mathrm{N}$ entering the gut are given below:

\begin{tabular}{lcccc}
\hline & $\begin{array}{c}\text { Single entry } \\
\text { g urea-N/d }\end{array}$ & $\begin{array}{l}\text { Multiple entry } \\
\text { g urea-N/d }\end{array}$ & SED & $P$ \\
\hline$P_{\mathrm{r}}$ & 1.28 & 3.35 & 0.193 & $<0.001$ \\
$F$ & 0.75 & 0.52 & 0.039 & $<0.001$ \\
$S$ & 5.99 & 4.15 & 0.019 & $<0.001$ \\
\hline
\end{tabular}

The multiple entry model yields a higher value for $P_{\mathrm{r}}$ and, in consequence, the amount of urea- $\mathrm{N}$ available for anabolic fates $S$ is smaller than for the single entry model. These findings contradict results by Sarraseca et al. (1998), due to an error in their single entry model. Furthermore, inclusion of faecal loss adjusts the estimate of $S$ by approximately $10 \%$.

From relatively uncomplicated experimental procedures, combined with a simple, but realistic, model that is applicable to both single shot and continuous infusion approaches, important information on the contribution of urea- $\mathrm{N}$ as an anabolic source of $\mathrm{N}$ was obtained.

The Scottish Office Agriculture, Environment and Fisheries Department is thanked for funding this research.

Jackson, A. A., Picou, D. \& Landman, J. P. (1984). The non-invasive measurement of urea kinetics in normal man by a constant infusion of ${ }^{15} \mathrm{~N}^{15} \mathrm{~N}$-urea. Clinical Nutrition 38C, 339-354.
Jackson, A. A., Danielsen, M. S. \& Boyes, S. (1993). A non-invasive method for measuring urea kinetics with a single dose of ${ }^{15} \mathrm{~N}^{15} \mathrm{~N}$-urea in free-living humans. Journal of Nutrition 123, 2129-2136.

Sarraseca, A., Milne, E., Metcalf, M. J. \& Lobley, G. E. (1998). Urea recycling in sheep: effects of intake. British Journal of Nutrition 79, 79-88.

\section{A transfer-function model to analyse solute transport in} soil in real time. M. A. MOJID, D. A. ROSE AND G. C. L. WYSEURE. Department of Agricultural \& Environmental Science, University of Newcastle, Newcastle upon Tyne NE1 7RU, UK

The increasing use of agrochemicals endangers the quality of land and groundwater. To assess possible pollution of the environment, it is necessary to characterize the transport of soluble chemicals through soils. The movement of solute over an extensive area is predicted using simulation models, which use local-scale solute-transport parameters, conventionally measured in the laboratory on disturbed soil volumes of the order of 1 litre, as inputs. The success of such models depends on the accuracy of the input parameters, so that accurate determination in situ of the solute-transport parameters is very important.

Solute transport is governed by the convectiondispersion equation (CDE) and the solute-transport parameters are determined by analysing the breakthrough curve of a tracer from a column of soil by various analytical or optimization techniques, e.g. CXTFIT (Parker \& van Genuchten 1984). However, despite its versatility, CXTFIT cannot estimate all three major solute-transport parameters [pore-water velocity $(v)$, dispersion coefficient $(D)$, retardation factor $(R)$ ] simultaneously: one of these parameters must be known previously, which may not be possible in many practical situations.

A transfer-function method has been developed that uses breakthrough data, measured using timedomain reflectometry, at two different vertical locations, separated by a distance $l$, from a pulse application of solute to the soil. The method predicts the response (at the lower location) by convoluting the input (at the upper location) in the time domain. The solute-transport parameters are determined by comparing the response predicted from the transfer function with that measured at the lower location.

For the one-dimensional CDE, a transfer function (Wakao \& Kaguei 1982, pp. 2, 10) may be written in terms of the mass dispersion number $(N=D / v l$, the reciprocal of the column Peclet number), the mean residence time of the tracer $(\tau=l / v)$, and $R$. The method allows the optimization in real time of $N, \tau$ and $R$ simultaneously and hence $v$ and $D$ because $l$ is known.

The new technique provided a better fit (smaller root-mean-square error) than CXTFIT between 
measured and estimated BTCs in all but one of 81 experiments $(3$ soil types $\times 3$ flow rates $\times 3$ solute concentrations $\times 3$ repetitions), and resulted in stable values of the transport parameters. When compared against five alternative methods of analysis, the new technique performed better in 54 of the experiments, i.e. $67 \%$. The method is robust against small errors in measurement and may also be used successfully with partial breakthrough curves.

Parker, J. C. \& Van Genuchten, M. T. (1984). Determining Transport Parameters from Laboratory and Field Tracer Experiments. Bulletin 84-3, Virginia Agricultural Experiment Station, Blacksburg, VA.

WakaO, N. S. \& KagueI, S. (1982). Heat and Mass Transfer in Packed Beds. New York: Gordon \& Breach.

Multiplicative probability models in seed physiology. A. J. MURDOCH, E. KEBREAB, L. SONKO AND I. P. LYNN. The University of Reading, Department of Agriculture, P.O. Box 236, Earley Gate, Reading RG6 6AT, UK

Seed-to-seed variation within seed lots is generally normally distributed. Examples include germination progress curves as a function of thermal time (Kebreab $\&$ Murdoch 1999b) and loss of viability during seed storage (e.g. Kebreab \& Murdoch $1999 c$ ).

However, sometimes responses are non-linear. An obvious example is for seeds in dry storage where loss of dormancy during dry after-ripening of seeds sometimes overlaps with loss of viability (Sonko \& Murdoch unpublished). In cases where the response of the individual seed is a binary effect (it either germinates or does not), nonlinear probability models seem appropriate. Key hypotheses of the non-linear models are: (i) seed-to-seed variation with respect to each component process is normally distributed with respect to the 'dose' variable (e.g. time); and (ii) the processes operate concurrently and independently within each individual seed. The assumption of independence has important consequences. Physiologically, it implies that the component processes have different physiological mechanisms. Mathematically, it implies that the response observed is described by a multiplicative probability model.

For example, imbibing seeds often show an initial sensitization to a subsequent stimulus, while prolonging the moist storage period results in a decreased response to subsequent stimulation. The principal processes in this latter case are loss of primary dormancy followed by induction of secondary dormancy (Totterdell \& Roberts 1979; Jones et al. 1997). The first attempt to quantify temperature effects during such processes by non-linear modelling was recently published (Kebreab \& Murdoch 1999a) for three weed species of Orobanche (broomrapes). A third concurrent process of loss of viability was included in the model in which final germination was the product of the probabilities that a seed: (i) has lost primary dormancy; (ii) has not entered secondary dormancy; and (iii) is still viable.

A similar model applies to Witchweed (Striga hermonthica, Sonko \& Murdoch unpublished) and the next stage is to apply the model to predict infestations of parasitic weeds in the field.

The model just described relates to seed dormancy. A similar model accounts for the effects of temperature on the germination of non-dormant seeds. Here, germination over a wide range of temperatures is a function of the probabilities that a seed: (i) is above its minimum temperature requirement for germination; and (ii) has not exceeded its maximum temperature for germination. This model has been applied to $O$. aegyptiaca at constant temperatures with the modifying effect of water stress being quantified, and secondly, to seeds in 169 thermal environments, where the effects of alternating temperatures have been quantified (Kebreab \& Murdoch submitted).

A further application of multiplicative probability models is the emergence of cleavers seed (Galium aparine) from different depths of burial in the soil. For seedling emergence, the two probabilities do not relate to dual processes but rather to two opposing effects of the depth of burial (Lynn \& Murdoch unpublished). Seeds must not be too close to the soil surface to avoid frequent wetting and drying or too much light, while if deeply buried the seedling may not have sufficient reserves to reach the soil surface. Emergence is then the product of the probabilities that a seed: (i) is not too close to the soil surface; and (ii) is not buried too deep.

Non-linear multiplicative probability models thus allow realistic modelling of concurrent binary responses of seeds.

Jones, S. K., Ellis, R. H. \& Gosling, P. G. (1997). Loss and induction of conditional dormancy in seeds of Sitka spruce maintained moist at different temperatures. Seed Science Research 7, 351-358.

Kebreab, E. \& Murdoch, A. J. (1999a). A quantitative model for loss of primary dormancy and induction of secondary in imbibed seeds of Orobanche spp. Journal of Experimental Botany 50, 211-219.

Kebreab, E. \& Murdoch, A. J. (1999b). Modelling the effects of water stress and temperature on germination rate of Orobanche aegyptiaca seeds. Journal of Experimental Botany 50, (334), (in press).

Kebreab, E. \& Murdoch, A. J. (1999c). Effect of moisture and temperature on the longevity of Orobanche seeds. Weed Research, (in press).

TotTerdell, S. \& Roberts, E. H. (1979). Effects of low temperatures on the loss of innate dormancy and the development of induced dormancy in seeds of Rumex obtusifolius L. and Rumex crispus L. Plant, Cell and Environment 2, 131-137. 
Descriptions of the lactation curve. N. C. FRIGGENS ${ }^{1}$ AND G. C. EMMANS ${ }^{2}$. ${ }^{1}$ Department of Animal Health and Welfare, Danish Institute of Agricultural Sciences, Research Centre Foulum, P.O. Box 50, DK-8830 Tjele, Denmark, ${ }^{2}$ Animal Biology Division, Scottish Agricultural College, Kings Buildings, West Mains Road, Edinburgh EH9 3JG, UK

Actual milk production curves are the consequence of two classes of effector: the inherent biology and genotype of the cow, here called potential; and environmental influences including limiting nutrition. The lactation curve arising when environmental effects are negligible, the potential lactation curve, provides a useful basis for characterizing the cow's innate biology. A general form for potential lactation curves is $Y=a u z$ where $Y$ is milk yield, $a$ a scalar, $u$ a growth function and $z$ a measure of competence. The extent to which the actual curve may deviate from the potential depends on the actual conditions of feeding, management and disease. Friggens et al. (1999) used daily yields for 240 days from calving for each of 40 cows in their first three lactations under good conditions (Veerkamp et al. 1994) to compare the functions of Wood (1967) and Emmans \& Fisher (1986). Wood's function has $z=\exp (-c t)$ and $u=t^{b}$ where $t$ is time from calving. The model of Emmans $\&$ Fisher (1986) has the same $z$ as Wood's function and $u=\exp \left(-\exp \left(G_{0}-B t\right)\right)$, giving $Y=$ $a \exp \left(-\exp \left(G_{0}-B t\right)\right) \exp (-c t)$. The same form was derived previously by France et al. (1985) to describe faecal marker excretion patterns. There was no difference in fitting ability between these two models (Friggens et al. 1999). In contrast, Rook et al. (1993) reported that the Emmans and Fisher model performed poorly (ranked 11th) relative to Wood's function (ranked 3rd) in their test of 13 models. However, the actual data used by Rook et al. (1993) would have, to a much larger extent, reflected nutritional environment rather than potential. Therefore, it is sensible to use actual data to test forms for potential curves only where conditions are likely to reflect potential.

The Emmans and Fisher model was also compared with the recently published model of Dijkstra et al. (1997). Dijkstra et al. (1997) proposed a mechanistic model of mammary gland development which led to the following function for the potential lactation curve: $\quad Y=M_{0} \exp \left(\mu_{T}(1-\exp (-k t)) / k-\lambda \tau\right)$. The residuals from fitting the two functions were identical. The two functions are mathematically the same as $a=M_{0} \exp \left(\mu_{T} / k\right), G_{0}=\ln \left(\mu_{T} / k\right), B=k$ and $c=\lambda$. Theories about a system at a high level may lead to functional forms which are essentially the same as those derived from assumptions about the presumed mechanisms. This implies that biological interpretability is a more useful quality of models than the extent to which they are mechanistic or empirical.
Dijkstra, J., France, J., Dhanoa, M. S., Maas, J. A., Hanigan, M. D., Rook, A. J. \& Beever, D. E. (1997). A model to describe growth patterns of the mammary gland during pregnancy and lactation. Journal of Dairy Science 80, 2340-2354

EMmans G. C. \& Fisher C. (1986). Problems in nutritional theory. In Nutrient Requirements of Poultry and Nutritional Research (Eds C. Fisher \& K. N. Boorman), pp. 9-39. London: Butterworth.

France, J., Thornley, J. H. M., Dhanoa, M. S. \& Siddons, R. C. (1985). On the mathematics of digesta flow kinetics. Journal of Theoretical Biology 113, 743-748.

Friggens, N. C., Emmans, G. C. \& Veerkamp, R. F. (1999). On the use of simple ratios between lactation curve coefficients to describe parity effects on potential milk production. Livestock Production Science, (in press).

Rook, A. J., France, J. \& Dhanoa, M. S. (1993). On the mathematical description of lactation curves. Journal of Agricultural Science, Cambridge 121, 97-102.

Veerkamp, R. F., Simm, G. \& Oldham, J. D. (1994). Effects of interaction between genotype and feeding system on milk production, feed intake, efficiency and body tissue mobilization in dairy cows. Livestock Production Science 39, 229-241.

Wood, P. D. P. (1967). Algebraic model of the lactation curve in cattle. Nature 216, 164-165.

Amino acid absorption and metabolism by the small intestine. J. A. MAAS, J. FRANCE AND L. A.CROMPTON. The University of Reading, Centre for Dairy Research, Department of Agriculture, Earley Gate, PO Box 236, Reading RG6 6AT, UK A biologically-based mechanistic mathematical model of amino acid (AA) absorption and metabolism by the small intestine has been developed. The first version of the model has been parameterized to the scale of the lactating dairy cow, however, the general structure is universally applicable to all species. Twenty individual AAs are represented in each of three distinct biological compartments: the small intestinal (SI) lumen; the enterocyte cytosol; and the blood perfusing the SI enterocytes respectively. All AA transport is represented bidirectionally and occurs via 7 AA transporters (Imino, B, A, ASC, $\mathrm{X}_{\mathrm{ag}}, \mathrm{L}, \mathrm{y}^{+}$) across the brush border membrane between the SI lumen and the enterocyte cytosol, and via 5 AA transporters (A, ASC, $\mathrm{X}_{\mathrm{ag}}, \mathrm{L}, \mathrm{y}^{+}$) (Guidotti \& Gazzola 1992, Mailliard et al. 1995) across the serosal side membrane between enterocyte cytosol and capillary blood. AA transporters exhibit saturable behaviour in vitro, and are therefore represented by MichaelisMenten saturation-type kinetic equations. Five of the AA transporters are $\mathrm{Na}^{+}$-dependent (Imino, B, A, ASC, $\mathrm{X}_{\mathrm{ag}}$ ), while the remaining 2 are $\mathrm{Na}^{+}$-independent $\left(\mathrm{L}, \mathrm{y}^{+}\right)$. Flux rates across the membranes are dependent on individual AA concentrations on both sides of the membrane, and additionally for the $\mathrm{Na}^{+}$dependent transporters, the $\mathrm{Na}^{+}$gradient across the membrane. Intracellular AA oxidation and transamination are explicitly represented. The utilization 
of AA for intestinal tissue protein synthesis, and the concomitant release of AA from tissue protein degradation (turnover) are described. The model can simulate the response to normal diurnal patterns of digesta flow to the duodenum and can accommodate different feeding patterns from once daily to continuous feeding. The model demonstrates how the small intestine can extract AAs from the small intestinal lumen, via the brush border membrane transporters or from the arterial blood supply via serosal membrane transporters. The quantity of AA transported through each membrane, at any given time, is dependent on the concentration gradient across the membrane and the rate of digesta flow through the small intestine. Variation in the profile of AA concentrations across the three adjacent compartments appears to be due to preferential absorption of certain AA, which is the direct result of the AA transporters present, and the concentration of AA presented to both sides of the enterocytes. Net uptake of some specific AA, particularly those transported by $\mathrm{Na}^{+}$-independent transporters, appears to be indirectly controlled by the uptake of AA associated with the $\mathrm{Na}^{+}$-dependent transporters.

Guidotti, G. G. \& Gazzola G. C. (1992). Amino Acid Transporters: Systemic Approach and Principles of Control. In Mammalian Amino Acid Transport: Mechanisms and Control (Eds M. S. Kilberg \& D. Häussinger), pp. 3-29. New York: Plenum Press.

Mailliard, M. E., Stevens B. R. \& Mann G. E. (1995). Amino-acid-transport by small-intestinal, hepatic, and pancreatic epithelia. Gastroenterology 108, 888-910.

Modelling tritrophic interactions for biological control. D. J. SKIRVIN, K. D. SUNDERLAND AND M. de COURCY WILLIAMS. Entomological Science Department, Horticulture Research International, Wellesbourne, Warwick CV35 9EF, UK

Biological control is becoming an increasingly favoured method for the control of crop pests, due to the increasing resistance of pests to insecticides and the increasing pressure to reduce the use of chemicals on crops. In ornamental crops grown under protection, the wide diversity of crop species and growing practices and low tolerance to crop damage, make the development of robust biological control strategies a challenge. In an attempt to respond to this challenge, a combined experimental and modelling approach is being used to gain an understanding of the key factors of tritrophic plant-pest-predator interactions that determine the efficiency of biological control in ornamental crops. The experimental work (Skirvin \& de Courcy Williams in press) has focused on three species of ornamental crops: Choisya ternata, Ceanothus' Autumnal Blue', and Euonymus japonicus, representing a range of different growth forms and leaf shapes; the spider mite pest, Tetranychus urticae and its predator, Phytoseiulus persimilis.
The model is an individual-based spatially explicit stochastic simulation, which uses a library of generic subroutines to describe the biology of both T. urticae and $P$. persimilis. The model is based on a previous model developed for edible glasshouse crops (Nachman 1987a, b). Development of the pests and predators is modelled using a Boxcar-train method (De Wit \& Goudriaan 1978), where the longevity of each instar is sampled from a uniform distribution, based on the experimental work. The fecundity of $T$. urticae is sampled from a normal distribution, with a mean and standard deviation derived from experimental data, whilst the fecundity of the $P$. persimilis is dependent upon the biomass of prey eaten.

Movement of the mites is determined by comparing the probability of movement assigned to each individual with a random value drawn from a uniform distribution. If the value of the random number is less than or equal to the probability of moving, the mite moves, with the direction being determined by the quartile within which the random value falls. The probability of movement is constant for nymphs of $T$. urticae, but is calculated from a binomial regression equation for both adult $T$. urticae and $P$. persimilis, since the movement of the latter two is correlated with the density of $T$. urticae.

Using a novel experimental method, involving cut stems and controls, the functional response of $P$. persimilis to $T$. urticae has been determined. The use of controls has made the analysis of the results more complicated, and instead of using a standard Holling functional response in the model, binomial regression models have been fitted.

Several introduction strategies have been examined using the model, and the results show that there are significant differences in outcome on the three plant species. Prey distribution also has a significant effect on the predicted outcomes of the model, as does repeated predator introductions. In order to develop successful biological control strategies for ornamental crops, more information about the effect of crop architecture on the movement of pest and predator will be needed.

The UK Ministry of Agriculture, Fisheries and Food funded this work.

De Wit, C. T. \& Goudrian, J. (1978). Simulation of Ecological Processes. Wageningen: Pudoc.

NaChMAN, G. (1987a). Systems analysis of acarine predatorprey interactions I: a stochastic simulation model of spatial processes. Journal of Animal Ecology 56, 247-265. NaChman, G. (1987 b). Systems analysis of acarine predatorprey interactions II: the role of spatial processes in system stability. Journal of Animal Ecology 56, 267-281.

Skirvin, D. J. \& DE Courcy Williams, M. (1999). Differential effects of plant species on a mite pest (Tetranychus urticae) and its predator (Phytoseiulus persimilis): implications for biological control. Experimental and Applied Acarology, (in press). 
Developmental impact of crop models in semi-arid tropics. E. KEBREAB, J. FRANCE AND R. H. ELLIS. The University of Reading, Department of Agriculture, P.O.Box 236, Earley Gate, Reading RG6 6AT, UK

Agricultural models have been developed in the UK for several years, but it is only since the late 1980s that modelling was considered appropriate to use in semiarid crop production systems. Four such crop models are evaluated here. PARCH (Crout et al. 1997), one of the first models developed specifically for application in the semi-arid tropics, simulates the growth and development of sorghum in response to different weather and soil conditions. PARCHED-THIRST (Young \& Gowing 1996), a model specializing in evaluating water-harvesting techniques, was developed for Tanzanian conditions and incorporates PARCH. EMERGE (Mullins et al. 1996), a crop emergence model, simulated emergence patterns in Tanzania. SWEAT (Daamen 1997), a crop-water balance model, simulates evapo-transpiration from sparse canopies in Niger. The four models are dynamic, deterministic and mechanistic, and the equations and notations used in the models are generally well structured, meaningful and concise.

Evaluation of the models, based on 161 questionnaires, showed that their uptake and impact in the semi-arid tropics were limited (Kebreab et al. 1998). The most probable reason for low uptake was lack of efficient dissemination and discontinuity in the information transfer-from model developers to experimental scientists (intermediate users) in the national research institutions, and to extension agents that would take it on to farmers (end-users). Lack of technical assistance for intermediate users also played a significant role in reducing the developmental impact of the models.

Suggestions for improvement include: (i) dissemination pathways identified before the start of the project so that the production of the model on a disk is not taken as the final output of the project; (ii) a strong link with at least one local institution in the target country both to encourage active participation in the development of the model and to act as a technical advisor once the project is completed; and (iii) evaluation of the model and its adaptation to the local environment by organizing a workshop that includes potential users as part of the dissemination process. The proceedings need to be published and circulated. A follow up of uptake and evaluation of impact need to be undertaken periodically. Technical improvement of models such as better user interface and standard input/output format are only successful if followed by effective dissemination.

The Natural Resources International Ltd and the Department for International Development (PD69) are thanked for funding this study.

Crout, N. M. J., Young, S. D. \& Bradley, R. G. (1997). PARCH-Technical Manual. The University of Nottingham, Department of Physiology \& Environmental Science, $70 \mathrm{pp}$.

DAMEN, C. C. (1997). Two source model of surface fluxes for millet fields in Niger. Agricultural and Forest Meteorology 83, 205-230.

Kebreab, E., France, J. \& Ellis, R. H. (1998). Evaluating The Potential Of Biomathematical Modelling Funded By DFID To Provide Developmental Impact In The Context Of NRSP Goals And Purposes, Final Technical Report. The University of Reading, Department of Agriculture, $73 \mathrm{pp}$.

Mullins, C. E., Townend, J., Mtakwa, P. W., Payne, C. A., Cowan, G., Simmonds, L. P., Daamen, C. C., Dunbabin, T. \& NaYlor, R. E. L. (1996). EMERGEUsers Guide. A Model To Predict Crop Emergence In The Semi-Arid Tropics. University of Aberdeen, Department of Plant \& Soil Science, $96 \mathrm{pp}$.

Young, M. D. B. \& GowIng, J. W. (1996). The PARCHEDTHIRST Model-User Guide version 1.0. University of Newcastle, Department of Agricultural \& Environmental Science, 109 pp. 